\title{
Compor imagens: clínica psicoterápica da melancolia e dos estados depressivos
}

\author{
Sylvia R. Fernandes*1
}

O artigo apresenta a modalidade de composição estética associada à psicanálise na clínica da depressão e da melancolia. Para tanto, analisa a relação da imagem visual com a palavra, $o$ ato como corte, a suplência na melancolia e a relação entre o sensório e o estético.

Palavras-chaves: Melancolia, depressão, composição estética, clínica psicanalítica

${ }^{* 1}$ Instituto Sedes Sapientiae (São Paulo, SP, Br). 
Uma mulher de aproximadamente cinquenta anos atravessa uma intensa crise melancólica. Afasta-se de suas atividades cotidianas e das pessoas com quem mantinha algum projeto. Seu rosto é o retrato de uma dor permanente. Em alguns momentos fixa e paralisa o olhar como se estivesse sendo invadida por algo terrificante. Porém, fica a impressão de que não há figura, mas o terror da iminência de um estar sem imagem e sem palavra, como se o ser estivesse se esvaindo num abismo.

É vivendo esse momento que inicia um processo psicanalítico, com sessões diárias. Diz estar sendo difícil, pois precisa falar de uma história e não há mais história alguma, nada faz sentido. Como falar de um passado se não há presente? Não acontece nada hoje, o que falar? O tempo foi suspenso.

Indagada sobre o que poderia se passar hoje, que fizesse alguma marca de acontecimento, relata que só consegue pensar em cores e linhas. Talvez bordar e, quem sabe, falar sobre isso. Assim, começa a bordar panos, inventa traçados e relata detalhadamente sobre o processo do fazer e das escolhas das cores. Um fio de história começa a ser tecido. Interessa-nos aqui pensar esta relação entre o sujeito tomado por estados depressivos e melancólicos agudos - nos quais a destruição da imagem de si leva-os à condição de viver à deriva - e a possibilidade de construção de marcas de acontecimentos, traços que podem ser significantes.

O trabalho formal com a matéria - seja palavra, corpo, som, matéria plástica, imagens visuais - , próprio do fazer artístico, é algo a ser considerado no funcionamento e estruturação subjetiva próprios da depressão e, principalmente, da melancolia.

A busca incessante pela palavra ou imagem artística perfeita e a insatisfação com o limite da linguagem, próprias do processo criativo de muitos artistas, podem ter relação com a melancolia e a permanente 


\section{ARTIGO}

nostalgia do objeto perdido. Vários pensadores tecem articulações entre a melancolia e o fazer artístico. ${ }^{1}$

Já no terreno do que é considerado hoje a depressão, também se observam articulações com a poesia e a arte em geral. Delouya (2002) afirma, a partir do testemunho de diferentes criadores ocidentais, serem a depressão e os estados depressivos ocasionais uma das mais ricas fontes da sensibilidade poética e artística. Para Berlinck \& Fédida (2000), o culto ao vazio próprio da depressão também fundamenta a busca de objetos de satisfação, inerente aos artistas românticos.

Há que se perguntar o que está implicado nesta relação melancolia/depressão e criação artística. Seria certa disposição artística própria destes estados psíquicos? Seria a melancolia, ou a depressão, condição própria do fazer artístico? Esta relação deve ser pensada para além de tal causalidade. Deslocar a questão da arte para a estética parece ser um caminho mais promissor, assim como pensar sobre um saber da verdade próprio destas configurações subjetivas e o da criação artística em geral.

Uma característica encontrada nestes estados subjetivos e no processo de criação de muitos artistas refere-se a um saber que muito se assemelha. Ambos se aproximam muito do perigo da verdade. Picasso (1993, p. 74) e Tarkovski (1990, p. 55), em diferentes momentos, dizem literalmente: "A arte é perigosa". Muitos artistas, em relatos sobre seus processos de criação, reconhecem que o caminho para a criação comporta uma zona de perigo. É um caminho que se dirige ao objeto, mas visa a Coisa. Picasso (1997) diz, "A pintura é a liberdade. De tanto saltar, podemos cair do lado mais fraco da corda. Mas se não nos arriscarmos a quebrar a cara, qual é a saída?" (p. 100). Se o limite é tênue, o que sustenta o sujeito não cair do outro lado da corda, como diz Picasso, ou, mais precisamente, não conseguir retornar de uma vivência de caos sem mediação, sem linguagem?

Para Lacan (1960/1991), “A verdadeira barreira que detém o sujeito diante do campo inominável do desejo radical uma vez que é o campo da destruição absoluta, da destruição para além da putrefação, é o fenômeno estético" (p. 265). E o fenômeno estético deve ser pensado para além da criação artística, como a qualidade do sentido, da sensação. ${ }^{2}$

Principalmente nos estados melancólicos, mas também em momentos agudos de depressão - em que o sujeito se encontra tomado pelo vazio - o mesmo perigo se coloca. É característica dos sujeitos que se colocam em uma posição

${ }^{1}$ Entre eles: Kristeva - a partir das obras de Holbein, Dürer, Dostoiévski, Nerval e Marguerite Duras; Le Poulichet - a partir dos processos de criação de Bram van Velde, Giacometti, Robert Walser e Fernando Pessoa; Lambotte - a partir de obras do filósofo Kierkegaard, Dürer, entre outros.

${ }^{2}$ A noção de estética utilizada aqui está de acordo com a concepção freudiana de teoria das qualidades do sentir e como a capacidade de dar forma a algo (Freud, 1919/1980). 
depressiva diante da vida o esvaziamento do sentido da existência. Sem projeto ou ideais que sustentem o sujeito, caem também, não no terror melancólico da perda de si, mas numa anestesia e imobilismo, como se assistissem sua vida congelada em uma cena sem movimento. Tudo se torna vazio. Desta forma, adquirem um saber notável sobre o vazio da existência e da condição humana. No ato criativo, na melancolia e na depressão corre-se o risco de se saber demais. O rei nu fica despido de si. Porém na arte, a forma artística volta a recobrir e a dar contorno ao sujeito.

Se a criação artística pode ser a possibilidade de sustentação para muitos que têm uma disposição à melancolia ou à depressão, o caminho da estética pode ser a saída para muitos outros que não têm a arte como condição existencial. Como poderíamos pensar uma clínica da melancolia e da depressão considerando esta dimensão estética?

\section{Projeto Compor}

Os entraves na constituição de representações psíquicas, tanto pelo colapso narcisista da depressão como pela dificuldade constitutiva da melancolia, afetam a linguagem. A palavra se vê reduzida a um descolamento significante. Trata-se de uma palavra vazia, uma exaustão da linguagem, como refere Fédida (2009). Tais sujeitos apresentam muita dificuldade associativa, muitas vezes em função de uma falta de confiança na palavra. Suas questões passam muito mais pela ameaça à existência, do que pela castração. A ênfase da função psicoterapêutica deve ser posta na constituição da representação, no caminho a ser trilhado da sensação à ideia. Como refere Cancina (1996), trata-se de buscar "aceder o imaginário à categoria de significante" (p. 82).

Considerando tais características, busca-se pesquisar a pertinência de uma clínica da depressão e da melancolia, que inclua um trabalho de composição estética, que funcione como o bordar para aquela mulher, ou seja, possa produzir acontecimentos que inscrevam marcas significantes.

Em agosto de 2013, inicia-se na Clínica Psicológica do Instituto Sedes Sapientiae, o Projeto Compor. Trata-se de um espaço de estudo e pesquisa sobre a depressão e a melancolia, e que oferece atendimento a pessoas que estejam com dificuldade de dar continuidade ou reinvestir os projetos e os ideais que dão sentido a suas vidas. Propõe uma clínica sustentada em dois pilares: o atendimento psicanalítico individual, concomitante ao atendimento em grupo na modalidade de composição estética. Este se realiza a partir da montagem de cenários bidimensionais com imagens, na maioria das vezes, fotográficas (as montagens são feitas individualmente e fora do espaço terapêutico). O grupo é o espaço onde tais cenários e o relato sobre o processo podem circular. 


\section{ARTIGO}

As imagens/figuras de interesse são recolhidas, recortadas e coladas justapostas ou sobrepostas sobre um suporte de papel. Ao serem retiradas do contexto original, as figuras são descaracterizadas do significado analógico e passam a ser elementos de um novo cenário.

A psicanálise possibilita ao sujeito a nomeação dos afetos vividos, a construção de uma história significante, por meio de uma apropriação da palavra, que vai sendo, pouco a pouco, investida ou reinvestida. Basicamente, o que se busca com este modelo de atendimento em dois espaços terapêuticos é constituir uma forma de linguagem, ancorada na relação da imagem visual com a palavra, na função do ato como recorte, na construção de um lugar de troca e circulação das produções próprias e na função de suplência na clínica da melancolia. Estes quatro vetores serão abordados a seguir.

\section{A imagem visual e a palavra}

A imagem visual sempre teve um lugar importante na psicanálise. Freud, já nos "Estudos sobre a histeria" (1893[1895]/1980), considerava que as lembranças reaparecem de maneira traumática, sob uma forma plástica e geralmente visual. Em seu estudo sobre as afasias (1889/2013), mostra como o vínculo da linguagem com o mundo sensível passa pelo olho (imagem visual do objeto) e pela fala (imagem acústica da palavra). Segundo Huot (1991), o registro simbólico para Freud não exclui o campo visual, e a imagem visual mantém uma relação direta com a fala.

Mas é nos estudos sobre os sonhos (1900/1980) que Freud articula claramente que o visual é da própria natureza do inconsciente. O sonho organiza as imagens em cena, sendo a figurabilidade um de seus quatro mecanismos constituintes. A plasticidade visual, própria do sonho, está ancorada em imagens sensoriais, que são, para Freud (1923/1980), o originário. A imagem situa-se, tanto onto como filogeneticamente, anterior à palavra. Há, portanto, a ideia de que o visual situa-se mais próximo do pulsional. Posteriormente, as palavras recobrem as imagens e as ideias são formadas.

A análise do sonho e sua sintaxe visam atravessar as cenas visuais em busca da fantasia que o sustenta. A cena é, portanto, uma tela de projeção da fantasia. E para Freud, segundo Huot, a tela privilegiada sobre a qual as fantasias são projetadas à vista de todos é a da criação artística. E principalmente o pintor é "quem melhor tornará sua fantasia "visível"” (Huot, 1991, p. 144). A cena imagética visual, seja nos sonhos, seja na criação artística, é um importante instrumento para a interpretação do inconsciente.

Uma mulher faz uma composição com figuras femininas que chamam muito a atenção. Ao buscar os trabalhos realizados anteriormente, reparei que havia certa 
repetição de um padrão de florzinhas delicadas, provavelmente retirado de fotografias de roupas de cama, colchas etc. Apenas pontuei verbalmente e mostrei como aquilo se repetia em vários cenários. No encontro seguinte, relata que, subitamente, após o grupo anterior, foi tomada por uma lembrança de uma cena infantil, há muito esquecida, em que ela viu uma cena, enigmática na época. Quando pequena, numa madrugada, desce as escadas da casa e vê a mãe com um homem na sala. O pai estava viajando. A mãe vestia um penhoar estampado de florzinhas. A pontuação sobre a repetição da figura possibilita uma abertura do inconsciente.

Porém, a relação da cena com a representação, deve ir além das possibilidades interpretativas. Há que tornar visível também outras cenas, cenas traumáticas, que situam-se fora, à margem da construção fantasmática do sujeito. Trata-se de fazê-las entrar em cena, revisitá-las, saindo do circuito da repetição em ato. Segundo Miriam Uchitel (2011), seria "reinscrever o trauma, dar-lhe representação. Sintomatizá-lo" (p. 192).

Em função de um acontecimento atual, uma mulher recorda uma cena traumática vivida na infância, em que, ao entrar no quarto da mãe, depara-se com esta deitada na cama meio desacordada, (devido às medicações que tomava para depressão), e uma mulher em pé com as mãos cheias de sangue. Tinha entrado no quarto pela janela, fugindo do marido que tentara matá-la. Faz uma reconstrução da cena plástica, como que para despotenciá-la. Diz ter tido a necessidade desta reconstrução e procura imagens que trazem estes elementos, fazendo uma composição da cena e acrescentando outras figuras. O resultado é uma cena onírica de forte impacto visual, com, entre várias imagens, a figura de uma mulher com as mãos com sangue e outra com um homem atacando uma mulher com um punhal. As colagens subsequentes trazem alguns destes elementos transfigurados. Numa, aparece também uma cena de um homem e uma mulher. Porém, esta figura, marcada por muito erotismo, traz uma mulher com uma espada nomeando um cavaleiro. Noutra colagem, várias imagens de mãos, podendo aqui não serem recobertas de sangue, mas como instrumentos de expressão. Mãos, espadas, homem e mulher - figuras que vão ganhando complexidades significantes ao longo do processo. A morte e a violência recobertas pela vida, pela sexualidade.

\section{O ato como recorte}

Lacan (1964/1998), privilegiando o processual do sujeito, dá ênfase à importância do ato. Assim, o sujeito está na cena. Ele diz, "no fundo do meu olho se pinta um quadro. O quadro certamente está no meu olho. Mas eu, eu estou no quadro" (p. 94). Estar no quadro é estar em cena, estar em ação. Deixa-se de ser espectador, aquele que olha. Faz-se outra cena. 


\section{ARTIGO}

No procedimento construtivo, a composição dos cenários deve ser tomada, para além de sua significação, pelo ato que a faz. Ao recolher imagens do mundo, o sujeito faz ato de separação. Ao se recortar figuras, ao apropriar-se delas, ao fazer outra coisa delas, opera-se um corte no real. Uma cena se faz, circunscrevendo um campo. Trata-se de dar forma ao informe, ao indiscriminado. Este ato de corte possibilita a representação.

Duas funções do ato podem ser consideradas na composição dos cenários. A primeira é a possibilidade de fazer limite ao outro, fazendo alguma figuração dele. Neste sentido tem a função de amenizar o domínio do outro. Tarkovski (1990) conta que fez o filme $O$ espelho a partir de imagens que eram recordações de sua infância, carregadas de muita energia emocional. A recordação da casa de sua infância vinha revestida de algo que o atormentava, algo sem registro. Sonhava frequentemente com esta casa. Após fazer o filme, diz, "recordações da infância que por tantos anos não me haviam deixado em paz, de repente desapareceram como que por encanto e, finalmente, deixei de sonhar com a casa em que vivera tantos anos atrás" (p. 152). Mais do que desaparecer, a imagem da casa se transforma, se torna forma. Faz ato de separação. A construção formal, pela materialização numa obra, limita o terror da indiscriminação no outro.

Uma mulher conta sobre seu processo de construção de uma cena. Recolhe imagens que a atraem, sem pensar no porquê da escolha, como uma associação livre em imagens. Compõe o cenário com várias figuras de pessoas em situações de equilíbrio instável. Corpos pendurados em andaimes, suspensos por fios em prédios altos, andando sobre fios, corpos como sombras. Diz que, de repente, sem pensar, coloca no centro a imagem de um corpo em queda livre. Neste momento é invadida por intensa emoção e susto, com seu corpo tomado por um tremor, entrando em contato com uma cena traumática de violência sexual vivida. A concretização plástica da cena e o olhar-se nela, faz com que seja imperioso, nos dias subsequentes, olhar novamente a imagem construída. Trata-se de dar forma ao vivido, podendo revisitar cenas com forte carga traumática e transfigurá-las ao longo de novas construções, nas quais os elementos vão tomando novas formas e significações. É uma possibilidade de manejo do traumático.

A segunda função que podemos considerar no ato de compor os cenários é a produção de uma marca, o próprio fato de inscrever que concretiza a existência do próprio sujeito. Por isso o júbilo do autor diante da obra, semelhante ao que Lacan descreve no estádio do espelho.

O júbilo diante da obra é algo muito recorrente nos processos criativos artísticos, mas estende-se a outras produções sublimatórias. Paulo Pasta (2002) diz, "a pintura está pronta quando eu posso me reconhecer nela (...), quando reproduz um pouco a maneira que eu sou" (p. 11). É o momento em que a obra construída reproduz a imagem do sujeito. O reconhecimento, função do eu, se dá a partir de 
algo de si que se apresenta num outro. Essa imagem produz júbilo porque, a partir dela, o sujeito ganha autoria. $\mathrm{O}$ que é refletido pode ser vislumbrado como próprio. Porém, ao se nomear na imagem do outro, se inscreve simbolicamente, marca um lugar de existência. O estádio do espelho também faz marca simbólica.

Uma mulher vive um momento de ruptura drástica com suas referências familiares, apartada violentamente de sua estrutura cotidiana. Permanece errando pela vida, sem morada fixa por mais de um ano (ficava circulando em casas de amigos). Vive um desmoronamento da imagem de si, perdendo as referências do que é. Num primeiro momento, quando nada fazia sentido para ela, traz ao grupo fotografias antigas dela e de seus familiares - registro do perdido, busca do que ainda restou da história deste corpo. Na sessão seguinte, traz uma colagem em que compõe elementos que podem ir sendo reconhecidos como próprios, o que gostava, ações de sustentabilidade, de ecologia, de reciclagem. O movimento é de buscar as marcas de reconhecimento deste corpo, reconstruir uma imagem de si. Seu processo tem a singularidade de ir acrescentando outros elementos na colagem anterior, como uma garantia de continuidade numa imagem ainda muito fragilizada.

Estas duas funções, o ato como separação e a produção de uma marca que atesta a existência do sujeito, estão implicadas na clínica psicanalítica em sentido estrito. A palavra é ato. Porém, em situações em que importantes falhas na constituição narcísica ameaçam a existência do sujeito, o trabalho com a matéria plástica/ visual pode produzir ou restabelecer o sentido da palavra. A própria materialidade do objeto evocativo e do objeto fabricado, que tem existência menos evanescente que a fala, pode permitir criar uma continuidade, uma permanência, importante função de sustentação psíquica nestes casos.

\section{A suplência na melancolia}

A clínica da melancolia deve ir além da constituição imaginária. A importante falha imaginária pode impossibilitar o melancólico de uma cura no sentido de uma compensação, restauração ou reconstrução do imaginário. Porém, uma construção estética poderia funcionar como uma resolução possível da melancolia? Neste caso, a montagem dos cenários teria um efeito imaginário de ordem estética, que funcionaria como uma suplência. A concepção teórica do objeto estético, para Lambotte, e a de objeto desconhecido, para Le Poulichet, podem servir de referências para esta função de suplência.

A função do objeto estético, para Lambotte (2001), é ser um objeto de contemplação, indicar o gozo. Pode se tratar de uma composição ou de uma organização estética, que pode ser feita a partir de uma organização dos objetos de uma casa 


\section{ARTIGO}

ou jardim, de uma coleção de objetos, de uma composição literária ou artística. Um olhar pousa sobre a realidade, dando a ela certo relevo, certa qualidade antes ignorada. Às vezes, um passeio na natureza e a percepção das tonalidades, do encanto sensível, pode ser objeto de discurso, antes tão nivelado. Isso permite, ao melancólico, "reintegrar a realidade" (p. 94).

Este objeto teria o estatuto de objeto metonímico para o sujeito melancólico. Não funciona como objetos metafóricos, que têm uma relação de substituição. O objeto metonímico não se distancia da coisa por substituições significantes. Ele a aponta permanentemente, indica o gozo da verdadeira realidade que está por trás. A realidade aparente do melancólico se apresenta plana, sem relevo, ilusória, muito longe do brilho e da verdade absoluta que, para ele, só alguns têm acesso. Porém, no momento em que se compõe ou recompõe um ambiente, certos objetos (coisas) reaparecem de forma surpreendente, como se os olhassem pela primeira vez. Para Lambotte, é sobre este olhar que parece se sustentar o prazer de alguns pacientes melancólicos.

No processo analítico, este campo estético, lugar de contemplação, é uma espécie de terceiro lugar entre o analista e o paciente, em que este pode descrever e partilhar seu ângulo de visão particular. Pode ser usado como um intermediário necessário. Segundo Lambotte (2001), "neste efeito imaginário, ele pensa que o analista, ele também, está interessado" (p. 92), o que pode possibilitar uma abertura para a transferência.

Le Poulichet (1998) também faz importantes considerações sobre a relação entre a criação e o desamparo, possibilitando uma abertura para a clínica da melancolia. A partir da análise de artistas plásticos e escritores, mostra o acontecer do ato criador como possibilidade de engendramento de objetos desconhecidos que assumem o estatuto de substitutos do eu. Segundo ela, "O objeto criado teria assim o poder de encarnar o substituto de uma superfície corporal, quando falhas narcísicas fazem impossível investir a 'projeção de uma superfície', que Freud assimila ao 'eu corporal"' (p. 7). Nas vivências de desamparo, que desintegram a imagem do eu, o objeto criado, ou objeto desconhecido, desloca a relação do perigo da dissolução para uma prática de viver em perigo por meio do ato criador. Trata-se de uma arte de viver em perigo.

Estes objetos suscitam a sua própria metamorfose ou recomposição em outros objetos singulares, que inventam novas superfícies do acontecer em devir, já que não parece possível o investimento narcísico de uma imagem de eu. São procedimentos para "tomar (ou recuperar) corpo, compondo superfícies corporais do acontecer nas quais se projetam substitutos do eu" (p. 17). Atuam como lugar de captação das forças pulsionais, fazendo borda ao gozo. Ou seja, possibilitam agrupar as pulsões parciais, que não podem ser canalizadas pela imagem do eu.

Um dos artistas plásticos analisados, Bram van Verde, diz que se espanta com o mundo visível e que está sempre fugindo. Este mundo visível, que possibilita sustentar-se e constituir uma imagem no espelho que é seu semelhante, "não é mais 
que uma ferida" (p. 24). Assim, buscar uma imagem de si é cair na ameaça de aniquilação, "o que já está representado se torna inevitavelmente esmagador” (p. 24).

Assim, estes substitutos do eu são sempre instáveis. Há que criar incessantemente. Criar seria surgir no instante enquanto objeto desconhecido, "o psíquico conhece ali uma efêmera eclosão" (p. 18). Trata-se então de conseguir corpo de maneira diferente que num espelho. Para Le Poulichet, a arte do perigo consiste em estar sempre à beira, no absolutamente instável. Estar em perigo anima a tensão de um corpo por vir, e, assim, não dissolvido. Como ela refere, "há que manter-se em movimento para não coincidir com uma imagem presa, para não correr o risco de coincidir consigo mesmo, porque esse 'si mesmo' parece identificado com um trauma" (p. 27). Assim, sacrifica-se a superfície de contato com o outro em vez de experimentar a ruptura traumática da superfície do eu.

\section{Do sensório ao estético}

Construir uma clínica a partir do uso conceitual tanto do objeto estético/ de contemplação como do objeto desconhecido/criado considera a importância da dimensão do ato e da encenação na melancolia e na depressão e faz da estética uma possibilidade subjetiva.

A dimensão estética presente nas construções teóricas de psicanalistas que se ocupam da clínica da melancolia e da depressão, seja a partir dos objetos de contemplação ou dos objetos criados, remete à relação do escópico com o visual. Tanto na melancolia como na depressão, de uma maneira geral, há certa disponibilidade às qualidades sensórias, mas isso não implica numa vivência de ordem estética propriamente.

Fédida (1999) descreve a vivência de um homem deprimido envolto em um imobilismo corporal e sua fala, no momento em que pôde fazer uso da palavra: "Quando eu ficava sentado por horas em minha poltrona ou na beirada da cama, sentia-me como que permeável e transparente à menor impressão do exterior" (p. 24). Delouya também relata a experiência sensível de um paciente, que posteriormente pôde verbalizá-la. A descrição de Delouya (2002) mostra bem a aderência sensória da vivência:

Ao entrar em casa, na volta de seu escritório, o paciente torna-se sensível a uma tonalidade peculiar da luz sobre a mesa da sala de jantar, levando alguns segundos antes de identificá-la como tal (...). O ar de família se desmantela, perde sentido. É a luz amarela, espalhada sobre a mesa, que enche agora todo o espaço, expondo uma tela branca de sua existência que está prestes a esfarelar-se num verdadeiro vazio. (p. 72)

Nas duas vivências, o sujeito fica tomado por uma qualidade, imantando-se a ela. Não se trata de uma composição estética e sim de uma captura, uma parada na 


\section{ARTIGO}

imagem. O tempo fica suspenso num congelamento da imagem. Aqui, o que está em pauta é um circuito pulsional autoerótico. Na melancolia, talvez até mais do que na depressão, a pulsão escópica se faz imperiosa. Os melancólicos estão sempre com o olhar perdido na distância, presos na certeza de que há algo mais luminoso a ser visto por trás da realidade aparente.

Quando Tarkovski põe em movimento a imagem da casa da infância, ele faz outra coisa dela. Descola-se da imagem, insere-a no tempo, podendo fazer uso de sua força sensória. Assim, descongela a imagem que o sidera, podendo deixar cair o olhar, como objeto escópico. A imagem ganha valor significante por meio de uma composição estética. Articular a pulsão escópica em cena rompe o circuito autoerótico, dá ao olhar o estatuto do visual, do especular. A vivência estética implica a ação do sujeito, implica estar no quadro, como diz Lacan. A composição estética, o trabalho com as montagens de cenários, poderia funcionar como a figuração da casa de Tarkovski, fazendo uso da sensibilidade sensória (tão comum nos sujeitos depressivos ou melancólicos) para a construção significante e/ou suplência imaginária.

Possivelmente na melancolia, na qual a dificuldade na função representativa tende a ser mais impeditiva, a criação estética poderia funcionar como organizadora das pulsões parciais, fazendo, de certa forma, a função do eu. Porém, na medida em que as falhas na função especular impossibilitam a construção de uma imagem de si - que possa dar corpo a uma marca própria —, esta suplência imaginária estaria sob o signo da instabilidade. Há que criar incessantemente.

A construção dos cenários e $\mathrm{o}$ atendimento psicanalítico poderiam fazer a função de ligação entre as impressões, sensações, imagens e palavras. Não se trata de superar ou ultrapassar a imagem sensória ou figura, substituindo-as pela palavra. Trata-se de dar corpo sensório à palavra, encarnando-a. É uma abertura de caminho entre a pulsão e o significante, por meio da composição estética e do processo psicanalítico.

\section{Referências}

Berlinck, M. T. \& Fédida, P. (2000, junho). A clínica das depressões: questões atuais. Revista Latinoamericana de Psicopatologia Fundamental, São Paulo, III(2), 9-25.

Cancina, P. (1996). A pesadez de uma adolescente. In U. T. Peres (Org.), Melancolia (pp. 73-88). São Paulo: Escuta.

Delouya, D. (2002). Depressão: estação psique. São Paulo: Escuta.

Fédida, P. (1999). Depressão. São Paulo: Escuta.

Fédida, P. (2009). Dos benefícios da depressão: elogio da psicoterapia. São Paulo: Escuta.

Freud, S. (1980a). Estudos sobre a histeria. In Edição Standard Brasileira das Obras Psicológicas Completas de Sigmund Freud (Vol. II). Rio de Janeiro: Imago. (Trabalho original publicado em 1893).

Rev. Latinoam. Psicopat. $\overline{\text { Fund., São Paulo, }}$ 17(4), 831-844, dez. 2014 
Freud, S. (1980b). O mecanismo psíquico do esquecimento. In Edição Standard Brasileira das Obras Psicológicas Completas de Sigmund Freud (Vol. III). Rio de Janeiro: Imago. (Trabalho original publicado em 1898).

Freud, S. (1980c). A interpretação dos sonhos. In Edição Standard Brasileira das Obras Psicológicas Completas de Sigmund Freud (Vol. IV). Rio de Janeiro: Imago. (Trabalho original publicado em 1900).

Freud, S. (1980d). O estranho. In Edição Standard Brasileira das Obras Psicológicas Completas de Sigmund Freud (Vol. XVII). Rio de Janeiro: Imago. (Trabalho original publicado em 1919).

Freud, S. (1980e). O ego e o Id. In Edição Standard Brasileira das Obras Psicológicas Completas de Sigmund Freud (Vol. XIX). Rio de Janeiro: Imago. (Trabalho original publicado em 1923).

Freud, S. (2013). Sobre a concepção das afasias: um estudo crítico. Belo Horizonte: Autêntica. (Trabalho original publicado em 1889).

Huot, H. (1991). Do sujeito à imagem: uma história do olho em Freud. São Paulo: Escuta.

Kristeva, J. (1989). O sol negro: depressão e melancolia. Rio de Janeiro: Rocco.

Lacan, J. (1991). O seminário. Livro 7. A ética da psicanálise. Rio de Janeiro: Jorge Zahar. (Trabalho original publicado em 1960).

Lacan, J. (1998). O seminário. Livro 11. Os quatro conceitos fundamentais da psicanálise. Rio de Janeiro: Jorge Zahar. (Trabalho original publicado em 1964).

Lambotte, M. C. (2000). Estética da melancolia. Rio de Janeiro: Cia. de Freud.

Lambotte, M. C. (2001, junho). A deserção do outro. Revista da Associação psicanalítica de Porto Alegre APPOA, Porto Alegre, XX, 84-101.

Le Poulichet, S. (1998). El arte de vivir em peligro: del desamparo a la creación. Buenos Aires: Nueva Visión.

Pasta, P. (2002). Notas sobre a pintura. Dissertação de mestrado em Artes. Escola de Comunicação e Artes da Universidade de São Paulo, São Paulo.

Picasso, P. (1993). Os artistas falam de si próprios. Lisboa: Dinalivros.

Picasso, P. (1997). Picasso - Vida e pensamentos. São Paulo: Martin Claret.

Tarkovski, A. (1990). Esculpir o tempo. São Paulo: Martins Fontes.

Uchitel, M. (2011). Neurose traumática. São Paulo: Casa do Psicólogo.

\section{Resumos}

(Composing Images: Psychotherapeutic clinic for melancholy and depressive dtates)

This paper discusses a combination of esthetic composition and psychoanalysis for treating depression and melancholia. The relationship between visual images and words, act as rupture, substitution in melancholia and the relationship between feeling and esthetics are discussed.

Key words: Melancholy, depression, esthetic composition, psychoanalytic clinic 


\section{ARTIGO}

(Composer des Images: la clinique psychothérapique de la mélancolie et les états dépressifs)

Cet article présente le mode de composition esthétique associé à la psychanalyse dans le traitement de la dépression et de la mélancolie. Dans ce but, on analyse le rapport entre les images visuelles et les mots, l'acte comme coupure, la suppléance dans la mélancolie et le rapport entre le sensoriel et l'esthétique.

Mots clés: Mélancolie, dépression, composition esthétique, clinique psychanalytique

(Componer Imágenes: clínica psicoterapéutica de la melancolía y de los estados depresivos)

El artículo presenta el modo de composición estética asociada con el psicoanálisis en el tratamiento de la depresión y de la melancolía. Se analiza la relación de la imagen visual con la palabra, el acto como un corte, la suplencia en la melancolía y la relación entre lo sensorial y lo estético.

Palabras claves: Melancolía, depresión, composición estética, clínica psicoanalítica

(Gestaltung von Bildern: psychotherapeutische Klinik der Melancholie und der Depressiven Zustände)

In diesem Beitrag wird die Modalität der ästhetischen Gestaltung in Zusammenhang mit der Psychoanalyse in der Klinik der Depression und der Melancholie vorgestellt. Dazu wird die Beziehung des visuellen Bildes zum Wort, dem Akt als (Ein-)Schnitt, die Stellvertretung in der Melancholie und das Verhältnis zwischen dem Sinnlichen und dem Ästhetischen untersucht.

Schlüsselwörter: Melancholie, Depression, ästhetische Gestaltung, psychoanalytische Klinik

Citação/Citation: Fernandes, S. R. (2014, dezembro). Compor imagens: clínica psicoterápica da melancolia e dos estados depressivos. Revista Latinoamericana de Psicopatologia Fundamental, 17(4), 831-844.

Editor do artigo/Editor: Manoel Tosta Berlinck

Recebido/Received: 21.3.2014/3.21.2014 Aceito/Accepted: 8.5.2014/ 5.8.2014

Rev. Latinoam. Psicopat. $\overline{\text { Fund., São Paulo, }}$ 17(4), 831-844, dez. 2014 
Copyright: (C) 2009 Associação Universitária de Pesquisa em Psicopatologia Fundamental/ University Association for Research in Fundamental Psychopathology. Este é um artigo de livre acesso, que permite uso irrestrito, distribuição e reprodução em qualquer meio, desde que o autor e a fonte sejam citados / This is an open-access article, which permits unrestricted use, distribution, and reproduction in any medium, provided the original authors and sources are credited.

Financiamento/Funding: A autora declara não ter sido financiada ou apoiada / The author has no support or funding to report.

Conflito de interesses/Conflict of interest: A autora declara que não há conflito de interesses / The author has no conflict of interest to declare.

\section{Sylvia R. Fernandes}

Psicanalista; Doutora em Comunicação e Semiótica pela Pontifícia Universidade Católica de São Paulo - PUC-SP (São Paulo, SP, Br); Coordenadora do Projeto Compor da Clínica Psicológica do Instituto Sedes Sapientiae (São Paulo, SP, Br).

Rua Jorge Americano, 472/202

05083-130 São Paulo, SP, Br

e-mail: sylviafernandes@uol.com.br 